\title{
The association of partial pressures of oxygen and carbon dioxide with neurological outcome after out-of-hospital cardiac arrest: an explorative International Cardiac Arrest Registry 2.0 study
}

Florian Ebner ${ }^{1 *}$ (D), Richard R. Riker², Zana Haxhija², David B. Seder², Teresa L. May², Susann Ullén ${ }^{3}$, Pascal Stammet ${ }^{4}$, Karen Hirsch ${ }^{5}$, Sune Forsberg ${ }^{6}$, Allison Dupont ${ }^{7}$, Hans Friberg ${ }^{8}$, John A. McPherson ${ }^{9}$, Eldar Søreide ${ }^{10,11}$, Josef Dankiewicz ${ }^{12}$, Tobias Cronberg ${ }^{13}$ and Niklas Nielsen ${ }^{1}$

\begin{abstract}
Background: Exposure to extreme arterial partial pressures of oxygen $\left(\mathrm{PaO}_{2}\right)$ and carbon dioxide $\left(\mathrm{PaCO}_{2}\right)$ following the return of spontaneous circulation (ROSC) after out-of-hospital cardiac arrest (OHCA) is common and may affect neurological outcome but results of previous studies are conflicting.

Methods: Exploratory study of the International Cardiac Arrest Registry (INTCAR) 2.0 database, including 2162 OHCA patients with ROSC in 22 intensive care units in North America and Europe. We tested the hypothesis that exposure to extreme $\mathrm{PaO}_{2}$ or $\mathrm{PaCO}_{2}$ values within $24 \mathrm{~h}$ after OHCA is associated with poor neurological outcome at discharge. Our primary analyses investigated the association between extreme $\mathrm{PaO}_{2}$ and $\mathrm{PaCO}_{2}$ values, defined as hyperoxemia $\left(\mathrm{PaO}_{2}>40\right.$ $\mathrm{kPa})$, hypoxemia $\left(\mathrm{PaO}_{2}<8.0 \mathrm{kPa}\right.$ ), hypercapnemia $\left(\mathrm{PaCO}_{2}>6.7 \mathrm{kPa}\right)$ and hypocapnemia $\left(\mathrm{PaCO}_{2}<4.0 \mathrm{kPa}\right)$ and neurological outcome. The secondary analyses tested the association between the exposure combinations of $\mathrm{PaO}_{2}>40 \mathrm{kPa}$ with $\mathrm{PaCO}_{2}<4.0 \mathrm{kPa}$ and $\mathrm{PaO}_{2} 8.0-40 \mathrm{kPa}$ with $\mathrm{PaCO}_{2}>6.7 \mathrm{kPa}$ and neurological outcome. To define a cut point for the onset of poor neurological outcome, we tested a model with increasing and decreasing $\mathrm{PaO}_{2}$ levels and decreasing $\mathrm{PaCO}_{2}$ levels. Cerebral Performance Category (CPC), dichotomized to good (CPC 1-2) and poor (CPC 3-5) was used as outcome measure.

Results: Of 2135 patients eligible for analysis, 700 were exposed to hyperoxemia or hypoxemia and 1128 to hypercapnemia or hypocapnemia. Our primary analyses did not reveal significant associations between exposure to extreme $\mathrm{PaO}_{2}$ or $\mathrm{PaCO}_{2}$ values and neurological outcome $(P=0.13-0.49)$. Our secondary analyses showed no significant associations between combinations of $\mathrm{PaO}_{2}$ and $\mathrm{PaCO}_{2}$ and neurological outcome $(P=0.11-0.86)$. There was no $\mathrm{PaO}_{2}$ or $\mathrm{PaCO}_{2}$ level significantly associated with poor neurological outcome. All analyses were adjusted for relevant co-variates.

(Continued on next page)
\end{abstract}

\footnotetext{
* Correspondence: florian.ebner@med.lu.se

'Lund University, Helsingborg Hospital, Department of Clinical Sciences Lund, Anesthesia and Intensive Care, Charlotte Yhlens Gata 10, S-251 87 Helsingborg, Sweden

Full list of author information is available at the end of the article
}

C C The Author(s). 2020 Open Access This article is licensed under a Creative Commons Attribution 4.0 International License, which permits use, sharing, adaptation, distribution and reproduction in any medium or format, as long as you give appropriate credit to the original author(s) and the source, provide a link to the Creative Commons licence, and indicate if changes were made. The images or other third party material in this article are included in the article's Creative Commons licence, unless indicated otherwise in a credit line to the material. If material is not included in the article's Creative Commons licence and your intended use is not permitted by statutory regulation or exceeds the permitted use, you will need to obtain permission directly from the copyright holder. To view a copy of this licence, visit http://creativecommons.org/licenses/by/4.0/. The Creative Commons Public Domain Dedication waiver (http://creativecommons.org/publicdomain/zero/1.0/) applies to the data made available in this article, unless otherwise stated in a credit line to the data. 
(Continued from previous page)

Conclusions: Exposure to extreme $\mathrm{PaO}_{2}$ or $\mathrm{PaCO}_{2}$ values in the first $24 \mathrm{~h}$ after OHCA was common, but not independently associated with neurological outcome at discharge.

Keywords: Oxygen, Carbon dioxide, Out-of-hospital cardiac arrest, Brain anoxia-ischemia, Cardio-pulmonary resuscitation, Critical care outcomes

\section{Introduction}

Admission to hospital as well as 30-day survival after out of hospital cardiac arrest (OHCA) has increased in recent years and most 30-day survivors after OHCA are discharged with good neurological function [1]. Despite these advances, the proportion of patients dying after hospital admission is more than $50 \%$ and the major causes are the primary ischemic cerebral injury sustained during the no-flow time of the OHCA and the additional secondary cerebral reperfusion injury that commences at return of spontaneous circulation (ROSC) [2, 3]. Reperfusion entails increased reactive oxygen species (ROS) production, mitochondrial dysfunction and apoptosis, and thus, exacerbates the detrimental consequences of the OHCA [3]. Targeted temperature management (TTM) has been suggested as an intervention to attenuate these effects but studies are inconclusive and current studies indicate varying use internationally [4-8]. Recent data suggest that elevated arterial partial pressure of carbon dioxide $\left(\mathrm{PaCO}_{2}\right)$, hypercapnemia, might improve neurological outcome after OHCA. Possible underlying mechanisms include decreased cerebral vascular resistance (CVR), increased cerebral blood flow (CBF), modulation of inflammatory processes and anti-convulsive properties [9-16]. In contrast to hypercapnemia, low $\mathrm{PaCO}_{2}$, hypocapnemia, increases CVR, decreases CBF, reduces oxygen delivery $\left(\mathrm{CDO}_{2}\right)$ and is associated with poor outcome [10, 16-19]. Low arterial partial pressure of oxygen $\left(\mathrm{PaO}_{2}\right)$, hypoxemia, is the primary source of neuronal injury occurring during the OHCA and a determinant of neurological outcome [3, 20]. Elevated $\mathrm{PaO}_{2}$, hyperoxemia, has also been associated with poor neurological outcome, possibly due to increased lipid oxidation, production of ROS, mitochondrial damage and reduced CBF [3, 21-23]. The association of combinations of extreme $\mathrm{PaO}_{2}$ and $\mathrm{PaCO}_{2}$ values after $\mathrm{OHCA}$ with outcome have less frequently been studied, but the combination of moderate hypercapnemia and mild hyperoxemia was association with improved neurological outcome in one study [24]. Overall study results are inconsistent and other investigations trying to confirm the protective or harmful associations of exposure to extreme $\mathrm{PaO}_{2}$ and $\mathrm{PaCO}_{2}$ values with neurological outcome were unable to do so [25-27]. Moreover, the available studies differ in methodology, inclusion criteria and may lack sufficient power. Therefore, we conducted this study of the International Cardiac Arrest Registry (INTCAR) 2.0 database to investigate the association between exposure to extreme $\mathrm{PaCO}_{2}$ and $\mathrm{PaO}_{2}$ values and neurological outcome at hospital discharge in a large cohort of adult, unconscious patients with sustained ROSC after OHCA.

\section{Methods}

INTCAR 2.0 is an international multicenter database including cardiac arrest patients admitted to intensive care units (ICU) at 22 medical centers in the United States and Europe. The present investigation of the INTCAR 2.0 database included prospectively collected cardiac arrest and treatment data from adult ( $\geq 18$ years of age), unconscious $(\mathrm{GCS}<8)$, OHCA patients with sustained ROSC. All patients in this study received TTM treatment and were admitted between 2008 and 2018. Patient data collected in the database was anonymized and OHCA data was reported according to the Utstein-style protocol [28]. Ethical committees in each participating country approved the data collection and analysis. Informed consent was either waived or obtained from all participants or relatives according to national and local standards, in line with the Helsinki declaration. Reporting of our analyses was guided by the STROBE recommendations [29].

\section{Definition of $\mathrm{PaO}_{2}$ and $\mathrm{PaCO}_{2}$ groups and data registration}

In the INTCAR 2.0 protocol, extreme $\mathrm{PaO}_{2}$ or $\mathrm{PaCO}_{2}$ exposure thresholds were defined as $\mathrm{PaO}_{2}>40 \mathrm{kPa}$, $\mathrm{PaO}_{2}<8.0 \mathrm{kPa}, \mathrm{PaCO}_{2}>6.7 \mathrm{kPa}$ and $\mathrm{PaCO}_{2}<4.0 \mathrm{kPa}$. Exposure to one or more extreme values during the first $24 \mathrm{~h}$ after ROSC was registered in a dichotomous manner (yes/no). The $\mathrm{PaO}_{2}$ and $\mathrm{PaCO}_{2}$ thresholds were aligned with previous studies [17, 21, 22]. Additionally, the single highest and lowest $\mathrm{PaO}_{2}$ values and the lowest $\mathrm{PaCO}_{2}$ value during the first $24 \mathrm{~h}$ after ROSC were documented, regardless of exposure level. In total 7 datapoints $\left(4 \mathrm{PaO}_{2}\right.$ and $3 \mathrm{PaCO}_{2}$ data-points) were collected per patient. For the purpose of this study we divided patients according to their extreme $\mathrm{PaO}_{2}$ or $\mathrm{PaCO}_{2}$ value exposure into four groups defined by the extreme values in the INTCAR 2.0 protocol; hyperoxemia $\left(\mathrm{PaO}_{2}>40\right.$ $\mathrm{kPa})$ hypoxemia $\left(\mathrm{PaO}_{2}<8.0 \mathrm{kPa}\right), \quad$ hypercapnemia $\left(\mathrm{PaCO}_{2}>6.7 \mathrm{kPa}\right)$ and hypocapnemia $\left(\mathrm{PaCO}_{2}<4.0 \mathrm{kPa}\right)$. Patients not exposed to extreme values were classified as 
$\mathrm{PaO}_{2}$ and $\mathrm{PaCO}_{2}$ no-exposure $\left(\mathrm{PaO}_{2}\right.$ 8.0-40 kPa and $\mathrm{PaCO}_{2} 4.0-6.7 \mathrm{kPa}$ ). Patients exposed to more than one extreme value were included in all exposure groups.

\section{Outcome}

To better compare with previous analyses [21, 22, 27, 30], cerebral performance category $(\mathrm{CPC})$ at discharge from hospital was chosen as primary outcome endpoint. After neurological assessment at hospital discharge by a trained health care professional OHCA patients were allocated to one of the five CPC categories, ranging from CPC1 (good cerebral performance/mild disability), CPC2 (moderate disability), CPC3 (severe disability), CPC4 (coma state) and CPC5 (brain death) [31, 32]. For this study we dichotomized outcome into good (CPC1 and 2) and poor (CPC3-5). Delayed outcomes, typically around 6 months after presentation, were also collected, by telephone interview or medical records.

In our primary analysis, we tested the association of exposure to extreme $\mathrm{PaO}_{2}$ or $\mathrm{PaCO}_{2}$ values with outcome. We conducted 8 analyses: 1.the hyperoxemia group was compared to the $\mathrm{PaO}_{2}$ no-exposure group and 2.to patients without hyperoxemia (no-hyperoxemia). The hypoxemia group was compared 3.to the $\mathrm{PaO}_{2}$ no-exposure group and 4.to patients not exposed to hypoxemia (no-hypoxemia). Patients in the hypercapnemia group were compared 5.to patients in the $\mathrm{PaCO}_{2}$ no-exposure group and 6.to patients without hypercapnemia exposure (no-hypercapnemia), while patients with hypocapnemia exposure were compared 7.to the $\mathrm{PaCO}_{2}$ no-exposure group and 8.to patients not exposed to hypocapnemia (no-hypocapnemia).

In previous studies, exposure to hyperoxemia, hypoxemia and hypocapnemia were associated with poor outcome while hypercapnemia was associated with good outcome $[13,18,21,22]$. In our secondary analyses we therefore, a priori, defined exposure groups to investigate these findings and compared patients exposed to the combination of hyperoxemia with hypocapnemia to a $\mathrm{PaO}_{2}$ and $\mathrm{PaCO}_{2}$ no-exposure group, followed by a $\mathrm{PaO}_{2}$ no-exposure group with hypercapnemia compared to the $\mathrm{PaO}_{2}$ and $\mathrm{PaCO}_{2}$ no-exposure group. Subsequently, we designed regression models with ascending and descending $\mathrm{PaO}_{2}$ values from $<20 \mathrm{kPa}$ to $>60 \mathrm{kPa}$ and $>8.0 \mathrm{kPa}$ to $<5.0 \mathrm{kPa}$ to define a possible threshold for the onset of the association of hyperoxemia or hypoxemia and poor outcome. We also designed a regression model for the onset of the association of hypocapnemia and poor outcome with descending $\mathrm{PaCO}_{2}$ values from $>4.0 \mathrm{kPa}$ to $<3.5 \mathrm{kPa}$.

\section{Sensitivity analyses}

Sensitivity analyses were performed for our primary analyses with all double exposed patients (hyperoxemia and hypoxemia or hypercapnemia and hypocapnemia) removed. Furthermore, we performed sensitivity analyses of our primary analyses, replacing outcome at discharge with long-term outcome at 6-month follow-up.

\section{Statistical analysis}

Proportions are presented as numbers and percentages and continuous variables as means with standard deviations (SD) or medians with interquartile ranges (IQR). Logistic regression analysis was used to assess the association between $\mathrm{PaO}_{2}$ and $\mathrm{PaCO}_{2}$ and neurological outcome at discharge. For the ascending analysis the odds ratio (OR) above the threshold was compared to the OR under the threshold, while for the descending analyses the OR under the threshold was compared to the OR above the threshold. All analyses were adjusted for pre-specified, and OHCA relevant co-variates: age (years), sex (male/female), previous chronic heart failure (yes/no), previous chronic obstructive pulmonary disease (COPD) (yes/no), cardiac arrest witnessed (yes/no), bystander cardiopulmonary resuscitation (yes/no), initial rhythm shockable (yes/ no), time to ROSC, admission GCS-M 1 vs $2-5$, circulatory shock, TTM-treatment (low, 32-34 degrees Celsius $\left({ }^{\circ} \mathrm{C}\right)$ versus high, $\left.35-37^{\circ} \mathrm{C}\right)$ and $\mathrm{pH}$ on admission as fixed effects and treatment site as a random effect. None of the independent variables included in our models were highly correlated. We conducted two-sided tests and considered a $P$-value $<0.05$ as significant. We included patients with complete data $\left(\mathrm{PaO}_{2}\right.$ and/or $\mathrm{PaCO}_{2}$ and $\mathrm{CPC}$ at discharge registered) in the primary and secondary analyses. However, for our long term outcome sensitivity analysis, we imputed missing outcome (last observation (CPC at discharge) carried forward). Analyses were conducted using R: A language and environment for statistical Computing (version 3.3.3 R Foundation for Statistical Computing, Vienna, Austria) [33].

\section{Results}

The INTCAR 2.0 database included 2162 OHCA patients who were assessed for eligibility. Of this cohort, we excluded 27 patients who experienced OHCA but were not unconscious on admission. The remaining 2135 patients were included in our final analysis (Fig. 1). Baseline data for this group is displayed in Table 1. Baseline data for the different $\mathrm{PaO}_{2}$ and $\mathrm{PaCO}_{2}$ exposure groups are displayed in the Additional File, Tables 1 and 2. Six hundred eighteen $(28.9 \%)$ patients experienced a good outcome and 1517 (71.1\%) a poor outcome. Eight hundred twenty-eight (38.8\%) patients were alive at discharge, while 1307 (61.2\%) were dead. At 6-month follow-up the outcome of 634 (29.7\%) patients was good, whereas 1501 (70.3\%) patients had a poor outcome in the cohort with imputed data. The cohort without imputation showed a good outcome in $450(24.3 \%)$ and a poor outcome in $1400(75.7 \%)$ patients. All patients received TTM treatment during the first $24 \mathrm{~h}$ after ROSC, 1673 (78.4\%) to target temperature 


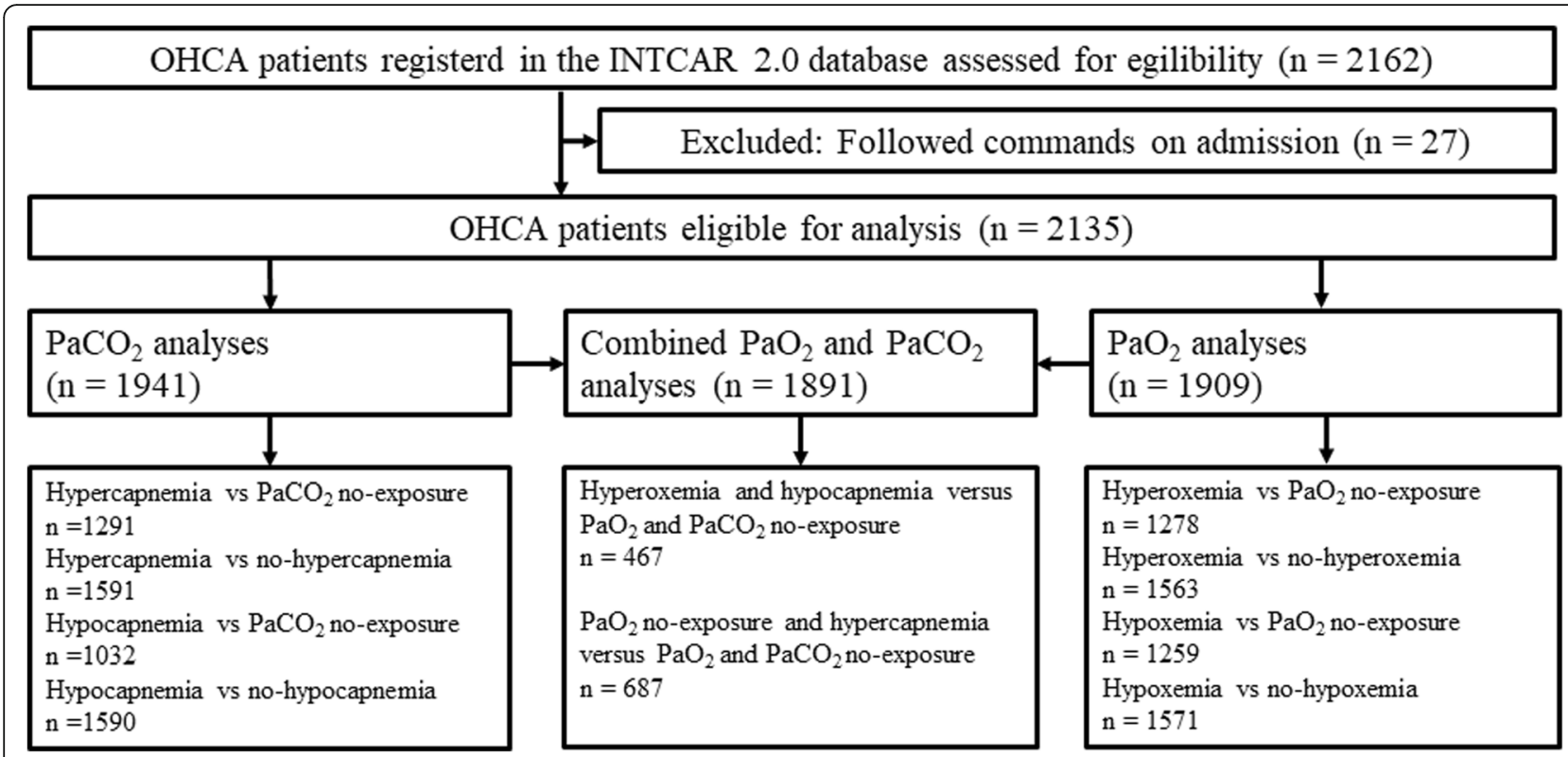

Fig. 1 Patient selection pathway. OHCA = out-of-hospital cardiac arrest, $n=$ number, $\mathrm{PaO}_{2}=$ arterial partial pressure of oxygen, $\mathrm{PaCO}$ arterial partial pressure of carbon dioxide, vs = versus

$32-34{ }^{\circ} \mathrm{C}$ and $462(21.6 \%)$ to $35-37^{\circ} \mathrm{C}$. Three hundred and fifty-seven (18.7\%) patients were exposed to hyperoxemia, $343(17.9 \%)$ patients to hypoxemia and $76(3.9 \%)$ to both, while $670(34.5 \%)$ patients experienced hypercapnemia, 458 (23.6\%) hypocapnemia and 222 (11.4\%) both. During the first 24 h after OHCA, median highest $\mathrm{PaO}_{2}$ was 25.7 (IQR 18.538.1) $\mathrm{kPa}$, median lowest $\mathrm{PaO}_{2}$ was 10.0 (IQR 8.1-12.7) $\mathrm{kPa}$ and median lowest $\mathrm{PaCO}_{2}$ was 4.3 (IQR 3.7-4.9) kPa.

In our primary analyses we found, after adjustment, neither hyperoxemia nor hypoxemia exposure in the first $24 \mathrm{~h}$ after ROSC to be associated with poor neurological outcome (all analyses, $P=0.13-0.44$ ) (Table 2). Exposure to hyper- or hypocapnemia during the first $24 \mathrm{~h}$ after ROSC was also not associated with poor outcome (all analyses, $P=0.18-0.49$ ) (Table 2).

In our secondary analysis the outcomes for patients exposed to the combination of hyperoxemia with hypocapnemia showed no association with poor neurological outcome $(P=0.11$, Table 3$)$. The exposure combination of hypercapnemia with $\mathrm{PaO}_{2}$ no-exposure was also not associated with poor outcome $(P=0.86$, Table 3$)$. Figure $2 \mathrm{a}$ and $b$ depict the adjusted OR with 95\% CIs for poor neurological outcome across ascending and descending $\mathrm{PaO}_{2}$ cut off values. Figure $2 \mathrm{c}$ shows the adjusted OR with 95\% CIs for poor neurological outcome across descending $\mathrm{PaCO}_{2}$ cut off values. We did not detect a significant threshold value for the onset of an association with poor outcome in any of these three analyses.

\section{Sensitivity analyses}

The results of the sensitivity analysis with all double exposed patients (hyperoxemia and hypoxemia or hypercapnemia and hypocapnemia) removed were similar to the results of our primary analyses $(P=0.07-0.29)$ (Additional File, Table 3$)$. Replacing outcome at discharge with long term outcome in our primary analyses did not change our results significantly, neither in the dataset without imputed outcome measures $(P=$ 0.14-0.89) nor in the dataset with missing outcome measures imputed $(P=0.13-0.59)$ (Additional File, Table 4 and 5).

\section{Missing data}

244 patients had one or more $\mathrm{PaO}_{2}$ or $\mathrm{PaCO}_{2}$ data points missing. Comparing this group with the group of patients with complete $\mathrm{PaO}_{2}$ and $\mathrm{PaCO}_{2}$ data $(n=1891)$ showed similar values at baseline (Additional File, Table 6).

\section{Discussion}

In this exploratory study testing the associations between exposure to extreme $\mathrm{PaCO}_{2}$ and $\mathrm{PaO}_{2}$ values and neurological outcomes at discharge of 2135 patients with $\mathrm{OHCA}$, we found that exposure to extreme $\mathrm{PaO}_{2}$ and $\mathrm{PaCO}_{2}$ values was common, but not significantly associated with neurological outcome after adjusting for in the context of OHCA-relevant covariates. In our subsequent analyses, we did not show any significant associations of combinations of $\mathrm{PaO}_{2}$ and $\mathrm{PaCO}_{2}$ and poor neurological outcomes. Despite investigating $\mathrm{PaO}_{2}$ values to $>60 \mathrm{kPa}$ and $<5.0 \mathrm{kPa}$ and $\mathrm{PaCO}_{2}$ values to $<3.5 \mathrm{kPa}$ in our ascending and descending cut-off point analyses, we did not identify a numerical threshold for the onset of the association of each variable with poor neurological outcome. These findings suggest that $\mathrm{PaO}_{2}$ and $\mathrm{PaCO}_{2}$ may not be directly associated with outcome after 
Table 1 Baseline characteristics of patients included in the $\mathrm{PaO}_{2}$ and $\mathrm{PaCO}_{2}$ analyses, $n=2135$

\begin{tabular}{|c|c|}
\hline Demographic characteristic & Value \\
\hline Age in years, mean (SD) & $61.09(15.9)$ \\
\hline Male sex, n (\%) & $1432(67.1)$ \\
\hline \multicolumn{2}{|l|}{ Medical history } \\
\hline Previous myocardial infarction $\mathrm{n}(\%)$ & $370(17.3)$ \\
\hline Chronic heart failure $\mathrm{n}(\%)$ & $367(17.2)$ \\
\hline COPD n (\%) & $344(16.1)$ \\
\hline Cerebro vascular disease n (\%) & $196(9.2)$ \\
\hline Diabetes mellitus n (\%) & $521(24.4)$ \\
\hline Obesity n (\%) & $268(15.3)$ \\
\hline \multicolumn{2}{|l|}{ Cardiac arrest characteristic } \\
\hline Witnessed cardiac arrest n (\%) & $1591(75.6)$ \\
\hline Bystander CPR n (\%) & $1385(65.5)$ \\
\hline Bystander defibrillation n (\%) & $123(5.8)$ \\
\hline Initial rhythm shockable n (\%) & $1022(50.0)$ \\
\hline Time to ROSC (min), median (IQR) & $29(21-48)$ \\
\hline \multicolumn{2}{|l|}{ Characteristic on arrival } \\
\hline Sedated on arrival n (\%) & $437(21.7)$ \\
\hline GCS Motor 1 n (\%) & $1544(79.4)$ \\
\hline Circulatory shock on admission n (\%) & $902(44.2)$ \\
\hline Admission pH, median (IQR) & $7.2(7.1-7.3)$ \\
\hline Admission lactate, mmol/l, median (IQR) & $6.4(3.2-10.2)$ \\
\hline Bicarbonate on admission, mmol/l, median (IQR) & $18.0(14.5-21.0)$ \\
\hline
\end{tabular}

Table 2 Association of exposure to extreme $\mathrm{PaO}_{2}$ and $\mathrm{PaCO}_{2}$ values with poor neurological outcome

\begin{tabular}{llll}
\hline Analysis & $\mathrm{OR}$ & $95 \% \mathrm{Cl}$ & $\boldsymbol{P}$-Value \\
\hline Hyperoxemia versus $\mathrm{PaO}_{2}$ no-exposure & 1.33 & $0.92-1.92$ & 0.13 \\
Hyperoxemia versus no-hyperoxemia & 1.25 & $0.88-1.77$ & 0.22 \\
Hypoxemia versus $\mathrm{PaO}_{2}$ no-exposure & 1.26 & $0.87-1.82$ & 0.22 \\
Hypoxemia versus no-hypoxemia & 1.15 & $0.81-1.64$ & 0.44 \\
Hypercapnemia versus $\mathrm{PaCO}_{2}$ no-exposure & 0.89 & $0.64-1.24$ & 0.49 \\
Hypercapnemia versus no-hypercapnemia & 0.86 & $0.64-1.15$ & 0.31 \\
Hypocapnemia versus $\mathrm{PaCO}_{2}$ no-exposure & 1.28 & $0.90-1.83$ & 0.18 \\
Hypocapnemia versus no-hypocapnemia & 1.23 & $0.91-1.66$ & 0.18 \\
\hline
\end{tabular}

OR odds ratio, $95 \% \mathrm{Cl} 95 \%$ confidence interval, $\mathrm{PaO}_{2}$ arterial partial pressure of oxygen, $\mathrm{PaCO}_{2}$ arterial partial pressure of carbon dioxide. Hyperoxemia = $\mathrm{PaO}_{2}>40 \mathrm{kPa}$, Hypoxemia $=\mathrm{PaO}_{2}<8.0 \mathrm{kPa}$, Hypercapnemia $=\mathrm{PaCO}_{2}>6.7 \mathrm{kPa}$, Hypocapnemia $=\mathrm{PaCO}_{2}<4.0 \mathrm{kPa}$. $\mathrm{PaO}_{2}$ no-exposure $=8.0-40 \mathrm{kPa}$ $\mathrm{PaCO}_{2}$ no-exposure $=4.0-6.7 \mathrm{kPa}$ resuscitation from OHCA. Animal studies have shown worse neurological outcomes and increased neurological injury after exposure to hyperoxemia following resuscitation from cardiac arrest and indicate that hyperoxemia in the post cardiac arrest phase might be harmful [34]. These findings have been corroborated by retrospective observational human studies [21, 35, 36]. Moreover, a threshold for the onset of poor outcome has been proposed at $40 \mathrm{kPa}$ [21]. Elmer et al. confirmed the previously suggested hyperoxemia threshold of $40 \mathrm{kPa}$ for the onset of poor outcome but also showed that moderate hyperoxemia $\left(\mathrm{PaO}_{2} 13.5-39.9 \mathrm{kPa}\right)$ was associated with lower SOFA scores at $24 \mathrm{~h}$, indicating a possibly beneficial effect at these levels [37]. This finding was supported by a study of Helmerhorst et al. investigating 5258 cardiac arrest patients, displaying a U-shaped relationship between $\mathrm{PaO}_{2}$ and outcome and, although not significant, the lowest probability of in-hospital death between $13.6-40 \mathrm{kPa}$ [38]. However, not all investigations support these results $[27,39]$, and studies are frequently of retrospective design, correct for different confounders and investigate mixed IHCA and OHCA cohorts.

A recent multi-center study of 280 patients across 6 hospitals in the United States by Roberts et al., sampled blood gases at 1 and $6 \mathrm{~h}$ after ROSC and found that early hyperoxemia was associated with poor outcome at discharge. The investigators also substantiated the suggested threshold for the onset of poor outcome at 40 $\mathrm{kPa}$. We investigated comparable $\mathrm{PaO}_{2}$ levels in our study and although our results were not significant, the point estimates of our primary analyses indicate higher probabilities for poor outcome in the hyperoxemia group but also in the hypoxemia group. We did not identify a significant threshold for the onset of poor neurological outcome in our cut-off analysis but the lowest probability of poor outcome was in the group exposed to a $\mathrm{PaO}_{2}$ of up to $20 \mathrm{kPa}$ which was similar to the risk ratio analysis by Roberts et al. Nevertheless, there are noteworthy differences between the investigations; our cohort was significantly larger than Roberts et al. and we included exclusively OHCA patients in order to increase homogeneity regarding cardiac arrest etiology. Furthermore, and most importantly, Roberts et al. sampled blood gases according to a prospective protocol over the first $6 \mathrm{~h}$ whereas our study evaluated the most extreme blood gas values during the first $24 \mathrm{~h}$ after ROSC.

Exposure to hypercapnemia or hypocapnemia in the post cardiac arrest phase is common [17, 18, 25, 40] and hypocapnemia has frequently been associated with poor outcome $[17,18,41]$ while hypercapnemia exposure has been associated with poor outcome [17, 30, 38, 42], good outcome $[12,13,18,24]$ or no difference in outcome $[25,41]$. In an analysis of 9176 adult OHCA patients 
Table 3 Association of $\mathrm{PaO}_{2}$ and $\mathrm{PaCO}_{2}$ combinations with poor neurological outcome

\begin{tabular}{llll}
\hline Analysis & $\mathrm{OR}$ & $95 \% \mathrm{Cl}$ & $\boldsymbol{P}$-Value \\
\hline Hyperoxemia and hypocapnemia versus $\mathrm{PaO}_{2}$ and $\mathrm{PaCO}_{2}$ no-exposure & 1.67 & $0.89-3.14$ & 0.11 \\
$\mathrm{PaO}_{2}$ no-exposure and hypercapnemia versus $\mathrm{PaO}_{2}$ and $\mathrm{PaCO}_{2}$ no-exposure & 0.96 & $0.63-1.48$ & 0.86
\end{tabular}

$\mathrm{OR}$ odds ratio, 95\% Cl 95\% confidence interval, $\mathrm{PaO}_{2}$ arterial partial pressure of oxygen, $\mathrm{PaCO}_{2}$ arterial partial pressure of carbon dioxide. $\mathrm{Hyperoxemia}=\mathrm{PaO}{ }_{2}>40$ $\mathrm{kPa}$, Hypoxemia $=\mathrm{PaO}_{2}<8.0 \mathrm{kPa}$, Hypercapnemia $=\mathrm{PaCO}_{2}>6.7 \mathrm{kPa}$, Hypocapnemia $=\mathrm{PaCO}_{2}<4.0 \mathrm{kPa} . \mathrm{PaO}_{2}$ no-exposure $=8.0-40 \mathrm{kPa}$,

$\mathrm{PaCO}_{2}$ no-exposure $=4.0-6.7 \mathrm{kPa}$

in the ROC-network, Wang et al. showed that hypercapnemia at any time-point within the first $24 \mathrm{~h}$ after OHCA and hypocapnemia towards the end of the first $24 \mathrm{~h}$ was associated with increased in-hospital mortality. Our study employed the same cut-off levels for hypercapnemia and hypocapnemia as Wang et al., but the prevalence of hypercapnemia and hypocapnemia were lower in our analysis $(34.5 \%$ versus 51.0 and $23.6 \%$ versus $30.6 \%$, respectively). The overall inhospital mortality of Wang et al. was similar to our proportion of patients with CPC5 at discharge $(67.3 \%$ versus $61.2 \%$ ), but we did not achieve significant results in our analyses, and somewhat contrary to the ROC-network analysis our point estimates indicate a lower probability for poor outcome in the group exposed to hypercapnemia. However, the studies are not entirely comparable; Wang et al. included significantly more patients and analyzed the first, last or any arterial blood gas measurement during the first $24 \mathrm{~h}$ of hospitalization, while our study analyzed the most extreme values within $24 \mathrm{~h}$ of ICU admission. Moreover, Wang et al. did not correct for in-hospital care such as induced hypothermia or physiological parameters as $\mathrm{pH}$.

Considering the results of the studies investigating $\mathrm{PaO}_{2}$ or $\mathrm{PaCO}_{2}$, the exposure to combinations of extreme $\mathrm{PaO}_{2}$ and $\mathrm{PaCO}_{2}$ values might also be associated with neurological outcome. Vahersaalo et al. found in a cohort of 409 OHCA patients the combination of moderate hypercapnemia and mild hyperoxemia to be associated with improved neurological outcome. We investigated hypercapnemia in combination with $\mathrm{PaO}_{2} 8.0-40 \mathrm{kPa}$, but were not able to show an association with an improved outcome in this group. Treatment with induced hypothermia to $32-34{ }^{\circ} \mathrm{C}$ might influence $\mathrm{CO}_{2}$ solubility and represent a potential bias between analyses, but the $32-34{ }^{\circ} \mathrm{C}$ groups were of similar size in both studies ( $71 \%$ versus $78.4 \%$ ). Nevertheless, there were significant differences, most notably, Vahersaalo et al. measured mean $\mathrm{PaO}_{2}$ and $\mathrm{PaCO}_{2}$ values in different ranges whereas we analyzed exposure to the most extreme values.

As shown above, studies investigating extreme $\mathrm{PaO}_{2}$ and $\mathrm{PaCO}_{2}$ value exposure after cardiac arrest differ in inclusion criteria and the time frame after ROSC, objectives

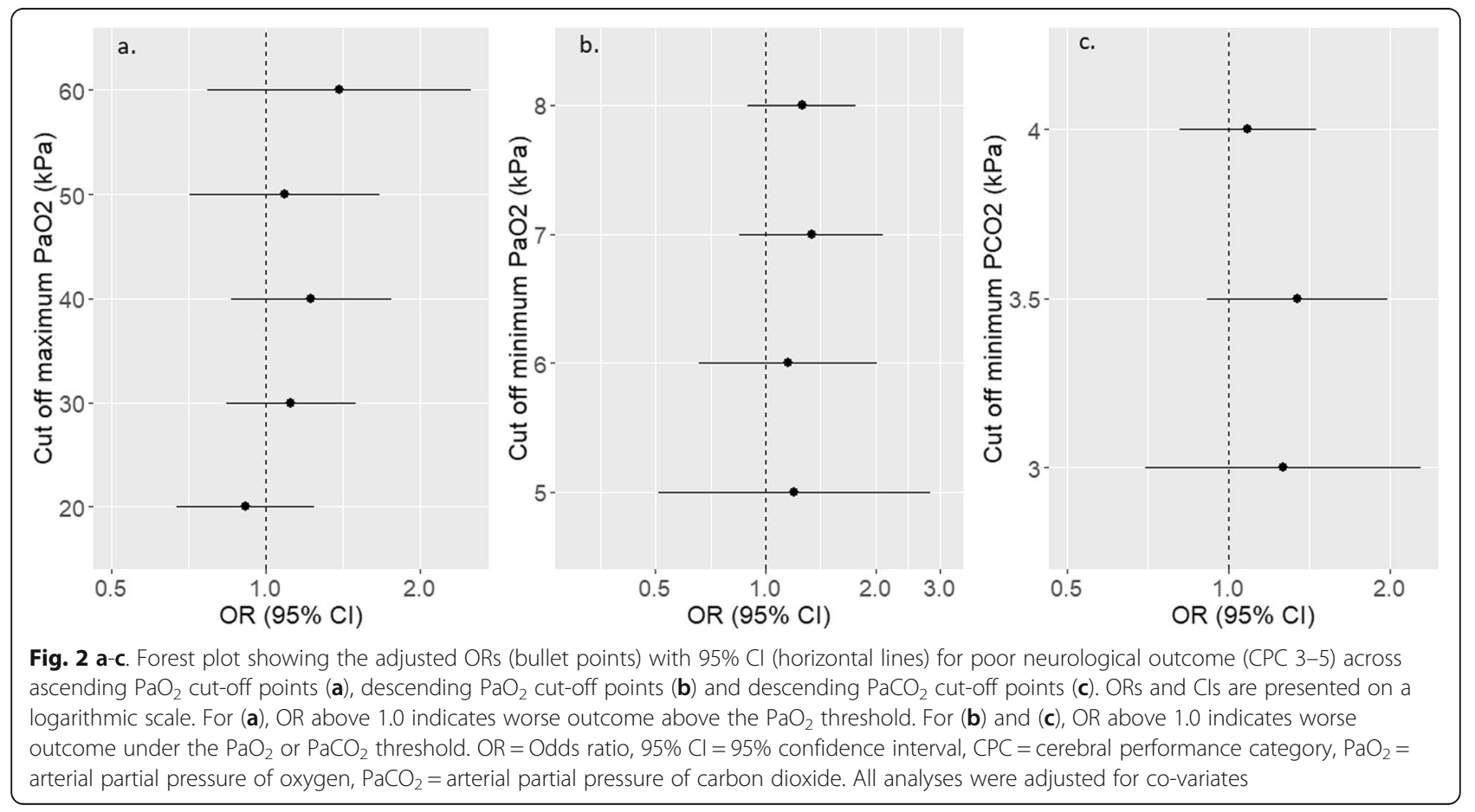


and results. Moreover, short term variability in vascular tone and acid-balance due changes in the fraction of inspired oxygen $\left(\mathrm{FiO}_{2}\right)$ or respiratory rate is commonly not accounted for [23, 43]. It seems also important to point out that the possible protective and harmful properties associated with exposure to extreme $\mathrm{PaO}_{2}$ and $\mathrm{PaCO}_{2}$ values are still of a largely hypothetical nature. Hypercapnemia increases $\mathrm{CBF}$ and might improve outcome by optimizing $\mathrm{CBF}$ and $\mathrm{CDO}_{2}$ after OHCA as suggested by Eastwood et al. [13, 15]. Hypercapnemia is also an effective anticonvulsant, suppressing neuronal activity in the central nervous system and potentially reducing neuronal metabolic demands following ROSC, but so far, hypercapnemia has failed to show an association with favorable EEG patterns after OHCA [9, 44-46]. The optimal dose of hypercapnemia in the post OHCA phase, if favorable, is not known. Two randomized controlled pilot-studies investigating high normal $\mathrm{PaCO}_{2}(5.8-6.0 \mathrm{kPa})$ and mild hypercapnemia $(6.7-7.3 \mathrm{kPa})$ have used neuron specific enolase (NSE) as a surrogate marker of neuronal injury $[13,44]$. NSE was significantly reduced in patients exposed to mild hypercapnemia, while high normal $\mathrm{PaCO}_{2}$ exposure was not associated with NSE levels after OHCA. Although, consistent high quality evidence is lacking, there are no indicators of harmful effects of controlled hypercapnemia exposure after OHCA [13, 25, 44]. However, the results of the present study conflict with results from previous investigations and support the need for further randomized trials $[47,48]$.

Neuronal metabolic failure due to hypoxemia during the no-flow period of the OHCA is the principal cause of cerebral damage, but also hyperoxemia following ROSC has been associated with neuronal injury, possibly due to increased production of ROS, lipid oxidation and decreased CBF $[3,49,50]$. In a randomized pilot trial, moderately elevated $\mathrm{PaO}_{2}$ levels $(20-25 \mathrm{kPa})$ did not influence NSE levels or neurological outcome after 6 months and exposure to $\mathrm{PaO}_{2}$ levels $\geq 40 \mathrm{kPa}$ following ROSC has not been investigated in a prospective randomized manner in humans [44]. However, randomized animal trials and observational human studies suggest harmful effects [12, 21, 34, 36, 37]. Our results do not support these findings entirely and randomized studies investigating increased levels of $\mathrm{PaO}_{2}$ in the post OHCA phase would be a possible way to further test the effect of $\mathrm{PaO}_{2}$ on outcome.

Our study has several limitations. Firstly, due to its observational design, the results are hypothesis generating and we cannot make causality statements. Secondly, we evaluated the most deviant $\mathrm{PaO}_{2}$ or $\mathrm{PaCO}_{2}$ values in the first $24 \mathrm{~h}$ after ROSC and were not able to analyze the exact exposure time-point, duration or to correct for acid-base parameters at the same time-point. Thirdly, in the statistical analyzes, our $P$-values were not significant on the 0.05 threshold level, but considering the direction of our point estimates and the width of the 95\% CI's, we cannot exclude a possible type II error and that there are associations that may have been statistically significant in a larger population [51]. We did not correct for $\mathrm{FiO}_{2}$ or $\mathrm{PaO}_{2} / \mathrm{FiO}_{2}$ ratios since $\mathrm{FiO}_{2}$ was not registered in the INTCAR 2.0 protocol and the $\mathrm{PaO}_{2} / \mathrm{FiO}_{2}$ ratio is rather an indicator for altered lung function, already accounted for by correcting for pre-existing COPD. The strengths of this study are the multicenter prospective design with 22 participating centers over two continents, a large cohort with over 2000 OHCA patients with extensive data regarding cardiac arrest characteristics and medical background and few excluded patients, as well as no missing outcome data in our primary and secondary analyses.

In summary, this study did not show an independent association of exposure to extreme $\mathrm{PaO}_{2}$ and $\mathrm{PaCO}_{2}$ values during the first $24 \mathrm{~h}$ after ROSC and neurological outcome at hospital discharge. The results of studies investigating exposure to extreme $\mathrm{PaO}_{2}$ and $\mathrm{PaCO}_{2}$ values vary widely and there is currently no consensus if extreme $\mathrm{PaO}_{2}$ or $\mathrm{PaCO}_{2}$ values are harmful, beneficial or innocuous to the post OHCA patient. The results of future prospective randomized studies are warranted before the existing recommendations on $\mathrm{PaO}_{2}$ and $\mathrm{PaCO}_{2}$ levels in the post OHCA phase can be revised [47, 52].

\section{Conclusion}

In a large cohort of patients resuscitated from OHCA, exposure to extreme $\mathrm{PaO}_{2}$ and $\mathrm{PaCO}_{2}$ values in the first 24 $\mathrm{h}$ after ROSC occurred commonly, but was not independently associated with neurological outcome at discharge.

\section{Supplementary information}

Supplementary information accompanies this paper at https://doi.org/10. 1186/s13049-020-00760-7.

\footnotetext{
Additional file 1: Table S1. Baseline characteristics of all patients and the $\mathrm{PaO}_{2}$ analysis groups. Table S2. Baseline characteristics of all patients and the $\mathrm{PaCO}_{2}$ analysis groups. Table S3. Sensitivity analysis. Association of exposure to extreme $\mathrm{PaO}_{2}$ and $\mathrm{PaCO}_{2}$ values with poor neurological outcome (Patients with extreme $\mathrm{PaO}_{2}$ or $\mathrm{PaCO}_{2}$ value double exposure removed). Table S4. Association of exposure to extreme $\mathrm{PaO}_{2}$ and $\mathrm{PaCO}_{2}$ values with poor neurological long term outcome. $n=1850$ Table S5. Association of exposure to extreme $\mathrm{PaO}_{2}$ and $\mathrm{PaCO}_{2}$ values with poor neurological long term outcome. Imputed values. $(n=2135)$ Table S6. Baseline characteristics of patients with complete $\mathrm{PaO}_{2}$ and $\mathrm{PaCO}_{2}$ values and patients with $\mathrm{PaO}_{2}$ or $\mathrm{PaCO}_{2}$ missing.
}

\section{Abbreviations}

$\mathrm{PaO}_{2}$ : Arterial partial pressure of oxygen; $\mathrm{PaCO}_{2}$ : Arterial partial pressure of carbon dioxide; TTM: Targeted temperature management; OHCA: Out-ofhospital cardiac arrest; ROSC: Return of spontaneous circulation; ROS: Reactive oxygen species; kPa: Kilopascal; CPC: Cerebral performance category; GCS: Glasgow coma scale; GCS-M: Glasgow coma scale - motor; SD: Standard deviation; IQR: Interquartile range; OR: Odds ratio; CBF: Cerebral blood flow; $\mathrm{CDO}_{2}$ : Cerebral oxygen delivery 


\section{Acknowledgements}

Study participants and staff of the following hospitals made this study possible: Central Maine Medical Center, Lewiston, USA; Columbia University, New York, USA; Eastern Maine Medical Center, Bangor, USA; Lehigh Valley Health Network, Allentown, USA; Maine Medical Center, Portland, USA; Stanford School of Medicine, Stanford, USA; Vanderbilt University Medical Center, Nashville, USA; The University of Arizona, Tucson, USA; Minneapolis Heart Institute, Minneapolis, USA; University of Michigan, Ann Arbor, USA; Northeast Georgia Medical Center, Gainesville, USA; Centre Hospitalier de Luxembourg, Luxembourg; Skåne University Hospital, Lund, Sweden; Falun Hospital, Falun, Sweden; Södersjukhuset, Stockholm, Sweden; Helsingborg Hospital, Helsingborg, Sweden; Blekingesjukhuset, Karlskrona, Sweden; Kalmar hospital, Kalmar, Sweden; Halmstad Regional Hospital, Halmstad, Sweden; Skaraborgs Hospital, Skövde, Sweden; Stavanger University Hospital, Stavanger, Norway.

\section{Authors' contributions}

FE and NN conceived this study. FE, NN and SU designed the statistical analyses. SU performed the statistical analyses. ZH, FE and JD prepared the data-files. FE wrote the first draft of the manuscript. All authors, except of SU, recruited patients and/or contributed to the data acquisition. All authors read, critically reviewed, and approved the final manuscript.

\section{Funding}

Dr. Ebner received an independent research grant from Stig och Ragna Gorthons Stiftelse and VO FoUU, Skånes sjukhus nordväst. Open access funding provided by Lund University.

\section{Availability of data and materials}

The datasets used and/or analysed during the current study are available from the corresponding author on reasonable request.

\section{Ethics approval and consent to participate}

Regional Ethical Review Board Lund, Sweden, Protocol 2007/7 Dnr 2007/272.

\section{Consent for publication}

Not applicable.

\section{Competing interests}

Dr. Friberg is scientific advisor at QuickCool. The remaining authors have disclosed that they do not have any conflicts of interest.

\section{Author details}

'Lund University, Helsingborg Hospital, Department of Clinical Sciences Lund, Anesthesia and Intensive Care, Charlotte Yhlens Gata 10, S-251 87 Helsingborg, Sweden. ${ }^{2}$ Department of Critical Care Services, Maine Medical Center, Portland, ME, USA. ${ }^{3}$ Clinical Studies Sweden, Skane University Hospital, Lund, Sweden. ${ }^{4}$ Medical and Health Directorate, National Fire and Rescue Corps, Luxembourg City, Luxembourg. ${ }^{5}$ Stanford Neurocritical Care Program, Department of Neurology and Neurological Sciences, Stanford University School of Medicine, Stanford, California, USA. ${ }^{6}$ Department of Intensive Care, Norrtälje Hospital, Center for Resuscitation,Karolinska Institute, Solna, Sweden. ${ }^{7}$ Department of Cardiology, Northeast Georgia Medical Center, Gainesville, GA, USA. ${ }^{8}$ Department of Clinical Sciences, Anesthesiology and Intensive Care, Lund University, Skane University Hospital, Malmö, Sweden. ${ }^{9}$ Vanderbilt University Medical Center, Nashville, TN, USA. ${ }^{10} \mathrm{Critical}$ Care and Anaesthesiology Research Group, Stavanger University Hospital, Stavanger, Norway. ${ }^{11}$ Department of Clinical Medicine, University of Bergen, Bergen, Norway. ${ }^{12}$ Department of Clinical Sciences Lund, Cardiology, Lund University, Skane University Hospital, Lund, Sweden.

${ }^{13}$ Department of Clinical Sciences Lund, Neurology, Lund University, Skane University Hospital, Lund, Sweden.

\section{Received: 14 January 2020 Accepted: 2 July 2020}

\section{Published online: 14 July 2020}

\section{References}

1. Stromsoe A, Svensson L, Axelsson AB, Claesson A, Goransson KE, Nordberg $P$, et al. Improved outcome in Sweden after out-of-hospital cardiac arrest and possible association with improvements in every link in the chain of survival. Eur Heart J. 2015;36(14):863-71.
2. Grasner JT, Lefering R, Koster RW, Masterson S, Bottiger BW, Herlitz J, et al. EuReCa ONE-27 nations, ONE Europe, ONE registry: a prospective one month analysis of out-of-hospital cardiac arrest outcomes in 27 countries in Europe. Resuscitation. 2016;105:188-95.

3. Sekhon MS, Ainslie PN, Griesdale DE. Clinical pathophysiology of hypoxic ischemic brain injury after cardiac arrest: a "two-hit" model. Crit Care. 2017; 21(1):90.

4. Nielsen N, Wetterslev J, Cronberg T, Erlinge D, Gasche Y, Hassager C, et al. Targeted temperature management at 33 degrees $C$ versus 36 degrees $C$ after cardiac arrest. N Engl J Med. 2013;369(23):2197-206.

5. Salter R, Bailey M, Bellomo R, Eastwood G, Goodwin A, Nielsen N, et al. Changes in temperature Management of Cardiac Arrest Patients Following Publication of the target temperature management trial. Crit Care Med. 2018:46(11):1722-30.

6. Bradley SM, Liu W, McNally B, Vellano K, Henry TD, Mooney MR, et al. Temporal trends in the use of therapeutic hypothermia for out-of-hospital cardiac arrest. JAMA Netw Open. 2018;1 (7):e184511.

7. Holzer M, Cerchiari E, Martens P, Roine R, Sterz F, Eisenburger P, et al. Mild therapeutic hypothermia to improve the neurologicoutcome after cardiac arrest. N Engl J Med. 2002;346(8):549-56.

8. Johnson NJ, Danielson KR, Counts CR, Ruark K, Scruggs S, Hough CL, et al. Targeted Temperature Management at 33 Versus 36 Degrees: A Retrospective Cohort Study. Crit Care Med. 2020;48:362-9.

9. Tolner EA, Hochman DW, Hassinen P, Otahal J, Gaily E, Haglund MM, et al. Five percent $\mathrm{CO}(2)$ is a potent, fast-acting inhalation anticonvulsant. Epilepsia. 2011;52(1):104-14.

10. Brian JE Jr. Carbon dioxide and the cerebral circulation. Anesthesiology. 1998;88(5):1365-86.

11. Keogh CE, Scholz CC, Rodriguez J, Selfridge AC, von Kriegsheim A, Cummins EP. Carbon dioxide-dependent regulation of NF-kappaB family members RelB and p100 gives molecular insight into CO2-dependent immune regulation. J Biol Chem. 2017;292(27):11561-71.

12. Hope Kilgannon J, Hunter BR, Puskarich MA, Shea L, Fuller BM, Jones C, et al. Partial pressure of arterialcarbon dioxide after resuscitation from cardiac arrest and neurological outcome: A prospective multi-center protocol-directed cohort study. Resuscitation.2019;135:212-20.

13. Eastwood GM, Schneider AG, Suzuki S, Peck L, Young H, Tanaka A, et al. Targeted therapeutic mild hypercapnia after cardiac arrest: a phase II multi-Centre randomised controlled trial (the CCC trial). Resuscitation. 2016;104:83-90.

14. Lennox W. The effect on epileptic seizures of varying the composition of the respired air. J Clin Invest. 1928;6:23-4.

15. Kety SS, Schmidt CF. The effects of altered arterial tensions of carbon dioxide on cerebral blood flow and cerebral oxygen consumption of normal young men. J Clin Invest. 1948;27(4):484-92.

16. Grune F, Kazmaier S, Stolker RJ, Visser GH, Weyland A. Carbon dioxide induced changes in cerebral blood flow and flow velocity: role of cerebrovascular resistance and effective cerebral perfusion pressure. J Cereb Blood Flow Metab. 2015;35(9):1470-7

17. Roberts BW, Kilgannon JH, Chansky ME, Mittal N, Wooden J, Trzeciak S. Association between postresuscitation partial pressure of arterial carbon dioxide and neurological outcome in patients with post-cardiac arrest syndrome. Circulation. 2013;127(21):2107-13.

18. Schneider AG, Eastwood GM, Bellomo R, Bailey M, Lipcsey M, Pilcher D, et al. Arterial carbon dioxide tension and outcome in patients admitted to the intensive care unit after cardiac arrest. Resuscitation. 2013;84(7):927-34.

19. Laffey JG, Kavanagh BP. Hypocapnia. N Engl J Med. 2002;347(1):43-53.

20. Dell'Anna A, Lamanna I, Vincent IL, Taccone F. How much oxygen in adult cardiac arrest? Crit Care. 2014;18(5):555.

21. Kilgannon JH, Jones AE, Shapiro NI, Angelos MG, Milcarek B, Hunter K, et al. Association between arterial hyperoxia following resuscitation from cardiac arrest and in-hospital mortality. JAMA. 2010;303(21):2165-71.

22. Roberts BW, Kilgannon JH, Hunter BR, Puskarich MA, Pierce L, Donnino M, et al. Association between early Hyperoxia exposure after resuscitation from cardiac arrest and neurological disability: prospective multicenter protocoldirected cohort study. Circulation. 2018;137(20):2114-24.

23. Watson NA, Beards SC, Altaf N, Kassner A, Jackson A. The effect of hyperoxia on cerebral blood flow: a study in healthy volunteers using magnetic resonance phase-contrast angiography. Eur J Anaesthesiol. 2000;17(3):152-9.

24. Vaahersalo J, Bendel S, Reinikainen M, Kurola J, Tiainen M, Raj R, et al. Arterial blood gas tensions after resuscitation from out-of-hospital cardiac 
arrest: associations with long-term neurological outcome. Crit Care Med. 2014;42(6):1463-70.

25. Ebner F, Harmon MBA, Aneman A, Cronberg T, Friberg H, Hassager C, et al. Carbon dioxide dynamics in relation to neurological outcome in resuscitated out-of-hospital cardiac arrest patients: an exploratory target temperature management trial substudy. Crit Care. 2018;22(1):196.

26. Ebner F, Ullen S, Aneman A, Cronberg T, Mattsson N, Friberg H, et al. Associations between partial pressure of oxygen and neurological outcome in out-of-hospital cardiac arrest patients: an explorative analysis of a randomized trial. Crit Care. 2019;23(1):30.

27. Bellomo R, Bailey M, Eastwood GM, Nichol A, Pilcher D, Hart GK, et al. Arterial hyperoxia and in-hospital mortality after resuscitation from cardiac arrest. Crit Care. 2011;15(2):R90

28. Perkins GD, Jacobs IG, Nadkarni VM, Berg RA, Bhanji F, Biarent D, et al. Cardiac arrest and cardiopulmonary resuscitation outcome reports: update of the Utstein Resuscitation Registry Templates for Out-of-Hospital Cardiac Arrest: a statement for healthcare professionals from a task force of the International Liaison Committee on Resuscitation (American Heart Association, European Resuscitation Council, Australian and New Zealand Council on Resuscitation, Heart and Stroke Foundation of Canada, InterAmerican Heart Foundation, Resuscitation Council of Southern Africa, Resuscitation Council of Asia); and the American Heart Association Emergency Cardiovascular Care Committee and the Council on Cardiopulmonary, Critical Care, Perioperative and Resuscitation. Circulation 2015;132(13):1286-300.

29. von Elm E, Altman DG, Egger M, Pocock SJ, Gotzsche PC, Vandenbroucke $J P$. The strengthening the reporting of observational studies in epidemiology (STROBE) statement: guidelines for reporting observational studies. Ann Intern Med. 2007;147(8):573-7.

30. Wang $\mathrm{CH}$, Huang $\mathrm{CH}$, Chang WT, Tsai MS, Lu TC, Yu PH, et al. Association between early arterial blood gas tensions and neurological outcome in adult patients following in-hospital cardiac arrest. Resuscitation. 2015;89:1-7.

31. Phelps R, Dumas F, Maynard C, Silver J, Rea T. Cerebral performance category and long-term prognosis following out-of-hospital cardiac arrest. Crit Care Med. 2013;41(5):1252-7.

32. Jennett $B$, Bond M. Assessment of outcome after severe brain damage. Lancet. 1975;1(7905):480-4.

33. Team RC. R : A language and environment for statistical computing. Austria URL https://www.R-projectorg/: R Foundation for Statistical Computing Vienna; 2017.

34. Pilcher J, Weatherall M, Shirtcliffe P, Bellomo R, Young P, Beasley R. The effect of hyperoxia following cardiac arrest - a systematic review and metaanalysis of animal trials. Resuscitation. 2012;83(4):417-22.

35. Kilgannon JH, Jones AE, Parrillo JE, Dellinger RP, Milcarek B, Hunter $K$, et al. Relationship between supranormal oxygen tension and outcome after resuscitation from cardiac arrest. Circulation. 2011;123(23):2717-22.

36. Janz DR, Hollenbeck RD, Pollock JS, McPherson JA, Rice TW. Hyperoxia is associated with increased mortality in patients treated with mild therapeutic hypothermia after sudden cardiac arrest. Crit Care Med. 2012:40(12):3135-9.

37. Elmer J, Scutella M, Pullalarevu R, Wang B, Vaghasia N, Trzeciak S, et al. The association between hyperoxia and patient outcomes after cardiac arrest: analysis of a high-resolution database. Intensive Care Med. 2015;41(1):49-57.

38. Helmerhorst HJ, Roos-Blom MJ, van Westerloo DJ, Abu-Hanna A, de Keizer $\mathrm{NF}$, de Jonge $\mathrm{E}$. Associations of arterial carbon dioxide and arterial oxygen concentrations with hospital mortality after resuscitation from cardiac arrest. Crit Care. 2015;19:348.

39. Ihle JF, Bernard S, Bailey MJ, Pilcher DV, Smith K, Scheinkestel CD. Hyperoxia in the intensive care unit and outcome after out-of-hospital ventricular fibrillation cardiac arrest. Crit Care Resusc. 2013;15(3):186-90.

40. Falkenbach P, Kamarainen A, Makela A, Kurola J, Varpula T, Ala-Kokko T, et al. Incidence of iatrogenic dyscarbia during mild therapeutic hypothermia after successful resuscitation from out-of-hospital cardiac arrest. Resuscitation. 2009;80(9):990-3.

41. Lee BK, Jeung KW, Lee HY, Lee SJ, Jung YH, Lee WK, et al. Association between mean arterial blood gas tension and outcome in cardiac arrest patients treated with therapeutic hypothermia. Am J Emerg Med. 2014; 32(1):55-60

42. Roberts BW, Kilgannon JH, Chansky ME, Trzeciak S. Association between initial prescribed minute ventilation and post-resuscitation partial pressure of arterial carbon dioxide in patients with post-cardiac arrest syndrome. Ann Intensive Care. 2014;4(1):9.
43. Bigatello L, Pesenti A. Respiratory physiology for the anesthesiologist. Anesthesiology. 2019;130(6):1064-77.

44. Jakkula P, Reinikainen M, Hastbacka J, Loisa P, Tiainen M, Pettila V, et al. Targeting two different levels of both arterial carbon dioxide and arterial oxygen after cardiac arrest and resuscitation: a randomised pilot trial. Intensive Care Med. 2018:44(12):2112-21.

45. Moonen $C$, Lemmens R, Van Paesschen W, Wilmer A, Eertmans W, Ferdinande $B$, et al. The impact of global hemodynamics, oxygen and carbon dioxide on epileptiform EEG activity in comatose survivors of out-ofhospital cardiac arrest. Resuscitation. 2018;123:92-7.

46. Xu F, Uh J, Brier MR, Hart J Jr, Yezhuvath US, Gu H, et al. The influence of carbon dioxide on brain activity and metabolism in conscious humans. J Cereb Blood Flow Metab. 2011;31(1):58-67.

47. Eastwood G, Nichol A, Bellomo R, Arabi Y. TAME cardiac arrest: a phase III multicenter randomized trial of targeted therapeutic mild hypercapnia after resuscitated cardiac arrest. Saudi Critical Care Journal. 2017;1(6):10-3.

48. Parke RL, McGuinness S, Eastwood GM, Nichol A, Nielsen N, Dankiewicz J, et al. Co-enrolment for the TAME and TTM-2 trials: the cerebral option. Crit Care Resusc. 2017;19(2):99-100.

49. Brucken A, Kaab AB, Kottmann K, Rossaint R, Nolte KW, Weis J, et al. Reducing the duration of $100 \%$ oxygen ventilation in the early reperfusion period after cardiopulmonary resuscitation decreases striatal brain damage. Resuscitation. 2010;81(12):1698-703.

50. Kwak DJ, Kwak SD, Gauda EB. The effect of hyperoxia on reactive oxygen species (ROS) in rat petrosal ganglion neurons during development using organotypic slices. Pediatr Res. 2006:60(4):371-6.

51. Altman DG, Bland JM. Absence of evidence is not evidence of absence. BMJ. 1995:311(7003):485.

52. Bray JE, Smith K, Hein C, Finn J, Stephenson M, Cameron P, et al. The EXACT protocol: a multi-Centre, single-blind, randomised, parallel-group, controlled trial to determine whether early oxygen titration improves survival to hospital discharge in adult OHCA patients. Resuscitation. 2019;139:208-13.

\section{Publisher's Note}

Springer Nature remains neutral with regard to jurisdictional claims in published maps and institutional affiliations.

Ready to submit your research? Choose BMC and benefit from:

- fast, convenient online submission

- thorough peer review by experienced researchers in your field

- rapid publication on acceptance

- support for research data, including large and complex data types

- gold Open Access which fosters wider collaboration and increased citations

- maximum visibility for your research: over $100 \mathrm{M}$ website views per year

At $\mathrm{BMC}$, research is always in progress.

Learn more biomedcentral.com/submission 